\title{
Effect of Decentration on the Optical Performance in Multifocal Intraocular Lenses
}

\author{
Mitsutaka Soda Shigeo Yaguchi \\ Department of Ophthalmology, University of Showa, Fujigaoka Rehabilitation Hospital, Yokohama, Japan
}

\author{
Key Words \\ Decentration - Multifocal intraocular lens - Eye model
}

\begin{abstract}
Aims: To evaluate the influence of decentration on optical performance in multifocal intraocular lenses (IOLs) using eye models. Methods: This study evaluated 4 types of multifocal IOLs (ReSTOR SA60D3, Alcon; TECNIS Multifocal ZM900, AMO; ReZoom, AMO; SFX-MV1, Hoya). The evaluations were based on measurements of the near and far modulation transfer function (MTF) and visualized actual near images (newspaper) using eye models with the IOL horizontally displaced $0,0.25,0.5,0.75$ and $1.0 \mathrm{~mm}$ from the center. Results: For the diffractive ReSTOR the near MTF decreased with increasing decentration. The near images (newspaper characters) became difficult to distinguish at a decentration of $1.0 \mathrm{~mm}$. For the diffractive ZM900, the near and far MTFs gradually decreased with increasing decentration. For the refractive ReZoom and SFX-MV1, we observed almost no change in the near MTF from a decentration of 0-1.0 mm. However, the far MTF clearly decreased starting at a decentration of $1.0 \mathrm{~mm}$ for ReZoom and $0.75 \mathrm{~mm}$ for SFX-MV1.

Conclusion: The MTFs and near images are affected to a dif-
\end{abstract}

\section{(c) 2012 S. Karger AG, Basel 0030-3755/12/2274-0197\$38.00/0 \\ Karger \\ Open access \\ This is an Open Access article licensed under the terms of} the Creative Commons Attribution- NonCommercial-NoDerivs 3.0 License (www.karger.com/OA-license), applicable to the online version of the article only. Distribution for non-commercial purposes only. ferent extent depending on the design of multifocal IOLs; clinically relevant effects are not to be expected up to a decentration of $0.75 \mathrm{~mm}$.

Copyright $\odot 2012$ S. Karger AG, Basel

\section{Introduction}

In recent years, there has been remarkable development in intraocular lenses (IOLs). New lenses improve quality of vision; contrast improvement by aspherical structure $[1,2]$, astigmatism correction $[3-5]$ and multifocal IOLs [6-11] have also been introduced.

Among these, multifocal IOLs are becoming increasingly common because they excel at enabling near vision. Multifocal IOLs include refractive and diffractive types, each having a characteristic structure, and many good clinical results have been reported for them [6-11]. Multifocal IOLs have more complex optical properties than monofocal IOLs do. In the optical component of an IOL, the near-sighted and far-sighted zones, which have different diffracting structures and refraction, are in concentric circles. 
Consequently, when a multifocal IOL is displaced from its center, there is concern that it will lose its ability to adequately achieve optical properties, and hence decrease visual function. Therefore, when a multifocal IOL is inserted, more attention is paid e.g. to the size or shape of the anterior capsulotomy than when a monofocal IOL is inserted, and evidently multifocal IOLs are not inserted in cases where decentration is expected, such as in cases of a brittle zonule of Zinn.

To study decentration of multifocal IOLs, Negishi et al. [12] have performed an optical simulation with Array (AMO), a refractive IOL that was a prior model of ReZoom (AMO). They evaluated the effects of up to $1.0 \mathrm{~mm}$ decentration of a monofocal IOL and Array, which is a refractive multifocal IOL. They evaluated the effects according to the visibility of a Landolt ring using eye models. Although we observed a decrease in contrast at a decentration of $1.0 \mathrm{~mm}$, it was possible to distinguish the Landolt rings, and there was no major decrease in visual function. In reports of clinical cases, Hayashi et al. [13] determined that when Array was used at a decentration exceeding $0.7 \mathrm{~mm}$, distance vision deteriorated, but that there was no correlation between decentration and near vision. However, since there are no reports about the effects of decentration on currently used multifocal IOLs, we think it is very important to investigate these effects.

Until now, we have been evaluating IOL performance by using eye models to perform optical simulations with multifocal IOLs [14-16]. In this study, we used optical simulations with eye models to objectively evaluate the effects of decentration of currently used multifocal IOLs. The evaluations were based on visualized actual near images and measurements of modulation transfer function (MTF). MTF is considered effective for evaluating optical properties. In the past as well, Kawamorita and Uozato [17] have reported an evaluation of a monofocal IOL and Array, which is a refractive multifocal IOL. The evaluation that we performed did not contradict clinical results; therefore, we thought that MTF was effective in evaluating visual function.

\section{Experimental Methods}

This study evaluated 4 types of multifocal IOLs: the diffractive ReSTOR SA60D3 (Alcon) and TECNIS Multifocal ZM900 (AMO), and the refractive ReZoom (AMO) and SFX-MV1 (Hoya). The near vision add powers of the multifocal IOLs were $+4.0 \mathrm{dpt}$ for ReSTOR, $+4.0 \mathrm{dpt}$ for ZM900, $+3.5 \mathrm{dpt}$ for ReZoom and +3.0 dpt for SFX-MV1 (fig. 1). Furthermore, the powers of the 4 types of IOLs were uniform at $+20.0 \mathrm{dpt}$.
In accordance with ISO regulations (ISO 11979-2), we used an automatic IOL-measuring device (Optispheric IOL, manufactured by Trioptics $\mathrm{GmbH}$ ) to measure MTF, which indicates the optical properties of IOLs (fig. 2a). We used a United States Air Force chart as an index (fig. 2b). A high-performance relay lens picks up this image and focuses onto the high-resolution chargecoupled device camera chip. The intensity profile of the target is scanned electronically in both the radial and tangential direction. The data is collected and, by using Fourier transform techniques, the MTF is calculated and displayed on the PC monitor in real time. The software calculates and displays the MTF value at selected spatial frequencies.

In this experiment, we used a 3-mm model pupil (aperture), set the IOL in eye models, and then measured the far and near MTFs with the IOL horizontally displaced $0,0.25,0.5,0.75$ and $1.0 \mathrm{~mm}$ from the center. Distance vision was at $5 \mathrm{~m}$ and near vision was at the optimal focal length (ReSTOR, ZM900: $30 \mathrm{~cm}$; ReZoom: $35 \mathrm{~cm}$; SFX-MV1: $40 \mathrm{~cm}$ ) of each IOL. An experienced researcher carried out all MTF measurements, took several measurements (at least twice), and confirmed that similar values were obtained.

For the simulation of the actual near-vision image, we used eye models that we had developed (fig. 3) $[15,16]$. The structure of the eye model consisted of a model cornea, a model pupil (aperture) and a main body. We created and used a 3-mm model pupil displaced $0,0.5$ and $1.0 \mathrm{~mm}$ from the center of the eye model, where the IOL was set. We inserted the model pupil with an attached IOL into the main body, filled it with water, installed a cornea on its anterior surface, and connected a charge-coupled device camera (Artray Inc.) to its posterior surface. The model cornea had a refractive power of $38.4 \mathrm{dpt}$ and a corneal aberration of $0.12 \mu \mathrm{m}$. The distance from the apex of the cornea to the surface of the IOL was about $6.0 \mathrm{~mm}$, and the distance from the apex of the cornea to the posterior surface of the eye model was $11.5 \mathrm{~mm}$.

Using newspaper characters as an index, we studied the actual effects of decentration. For the measurement method, we focused the camera on a point $5 \mathrm{~m}$ away from the index. Then we took an image at the optimal distance for each IOL from the camera to the index.

\section{Results}

\section{Near MTF}

Figure 4 shows the near MTF (50 cycles $/ \mathrm{mm}$ ) at each IOL decentration of $0-1.0 \mathrm{~mm}$. Table 1 shows MTF measurement values at $50 \mathrm{cycles} / \mathrm{mm}$ for each IOL. The near MTF of the diffractive ReSTOR decreased with increasing decentration and decreased the most at a decentration of $1.0 \mathrm{~mm}$. The near MTF of the diffractive ZM900 decreased slightly, beginning at a decentration of about 0.5 $\mathrm{mm}$, but the relative change was small. As for the near MTF of the refractive ReZoom and SFX-MV1, we did not observe much of a decrease in near MTF due to decentration. 


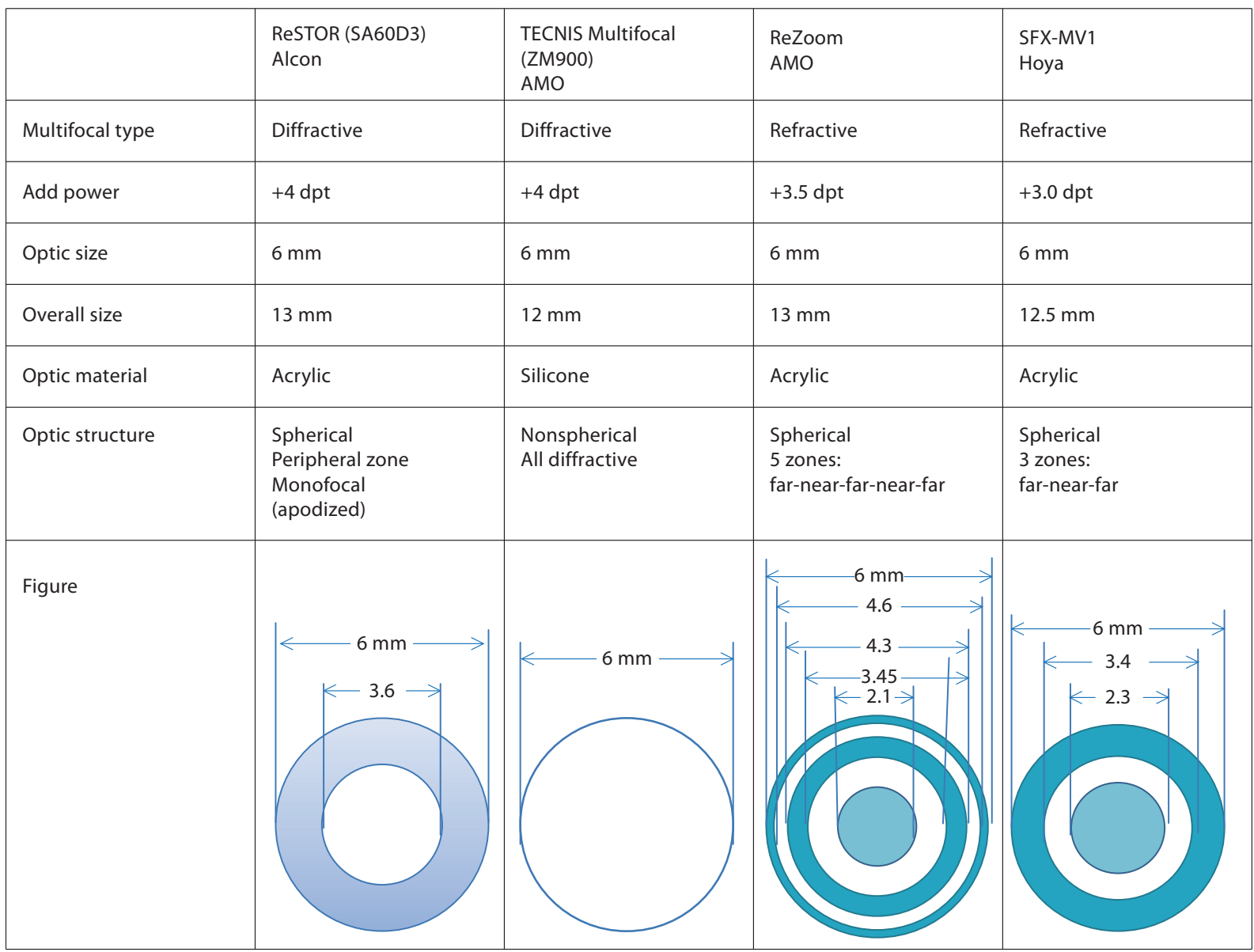

Fig. 1. Optical design data of multifocal IOLs.

Fig. 2. a An automatic MTF-measuring device (Optispheric IOL). b United States Air Force chart.
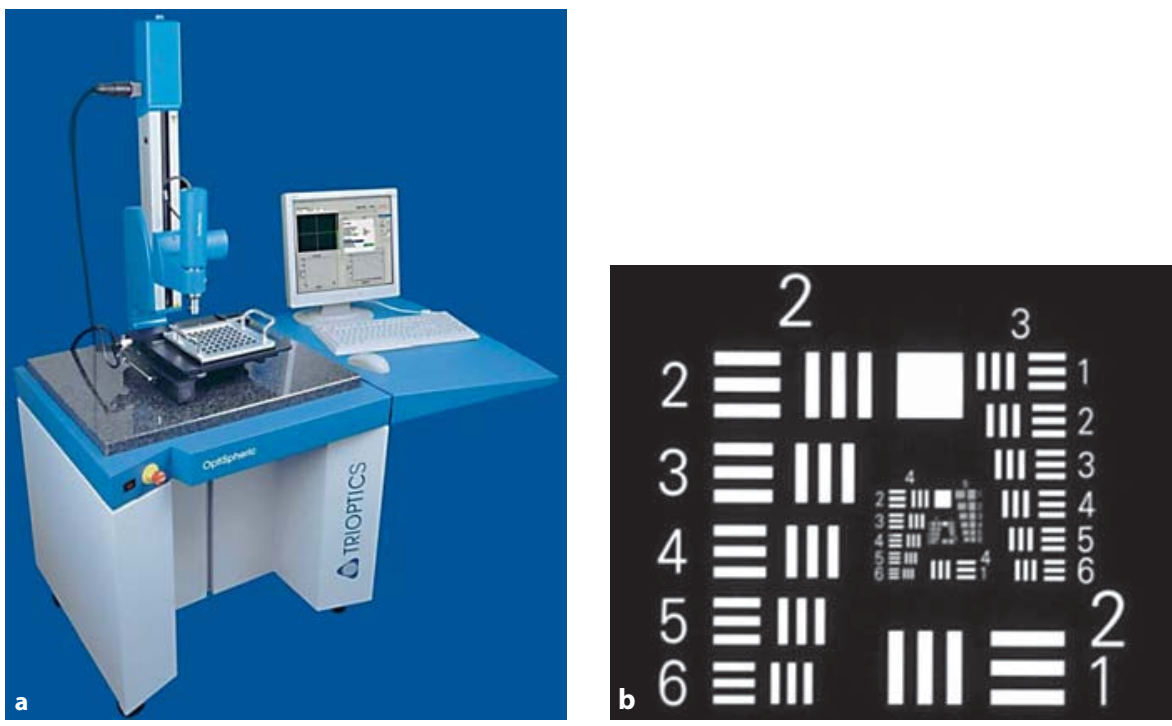
Fig. 3. The structure of the eye model. a Eye model main body and model cornea. b A model pupil horizontally displaced 0 , 0.5 and $1.0 \mathrm{~mm}$ from the center. c Chargecoupled device (CCD) camera. d Simulation of visibility of the newspaper.
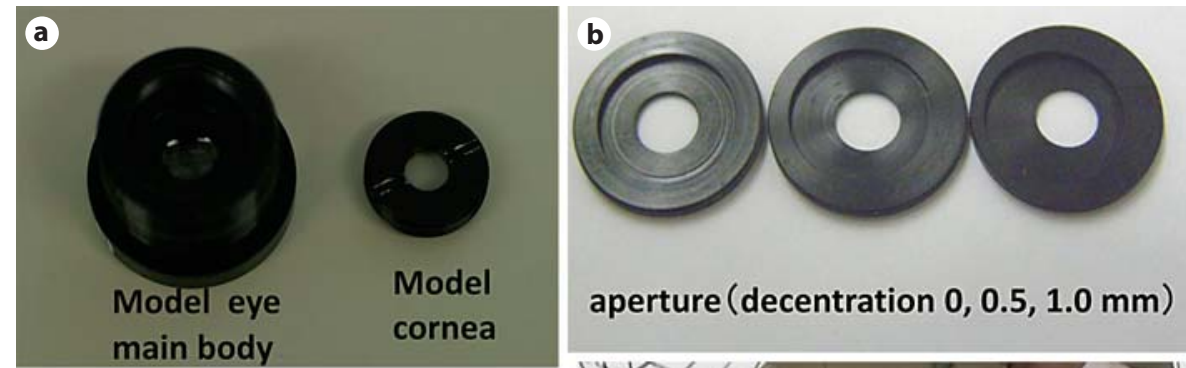

aperture (decentration $0,0.5,1.0 \mathrm{~mm}$ )
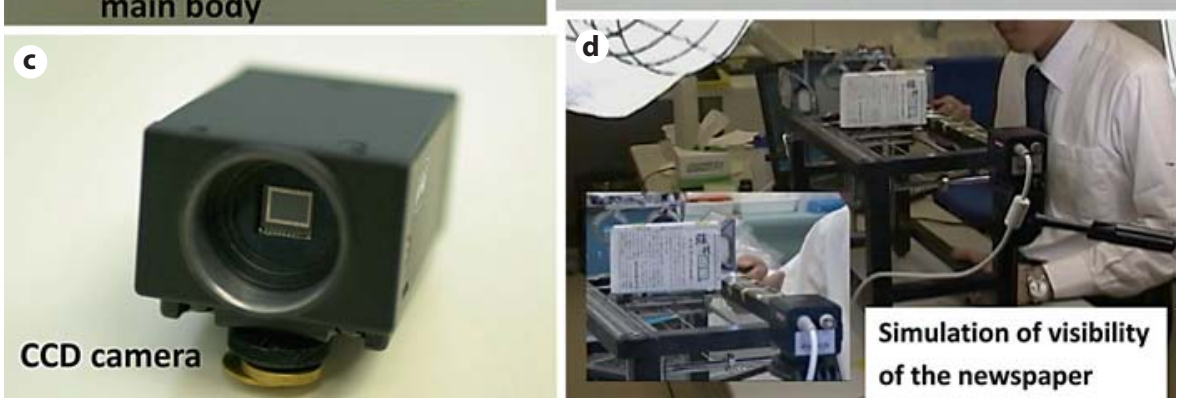

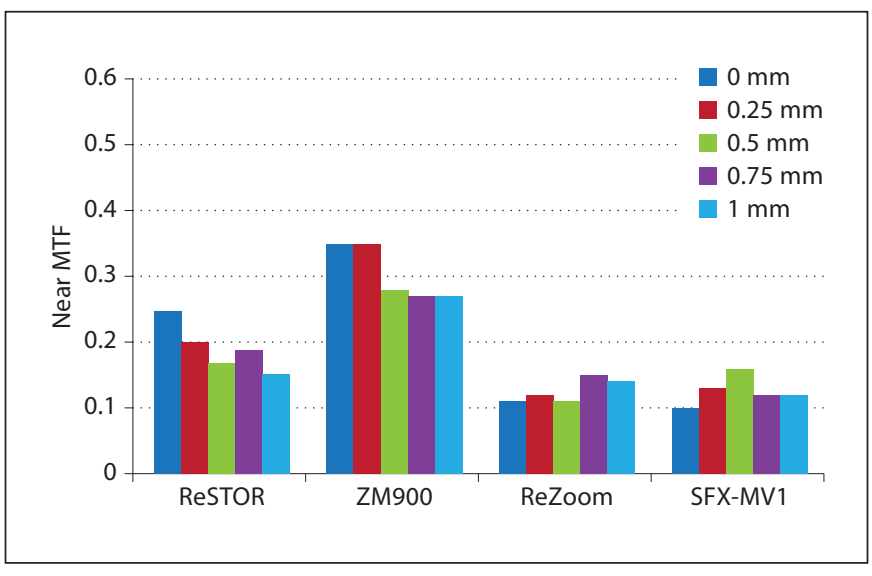

Fig. 4. Near MTF at $50 \mathrm{cycles} / \mathrm{mm}$ for each IOL up to decentrations of $0-1.0 \mathrm{~mm}$.

Table 1. Near MTF measurement values at $50 \mathrm{cycles} / \mathrm{mm}$ for each IOL

\begin{tabular}{lllll}
\hline & ReSTOR & ZM900 & ReZoom & SFX-MV1 \\
\hline Decentration 0 mm & 0.25 & 0.35 & 0.11 & 0.1 \\
Decentration 0.25 mm & 0.2 & 0.35 & 0.12 & 0.13 \\
Decentration $0.5 \mathrm{~mm}$ & 0.17 & 0.28 & 0.11 & 0.16 \\
Decentration $0.75 \mathrm{~mm}$ & 0.19 & 0.27 & 0.15 & 0.12 \\
Decentration $1 \mathrm{~mm}$ & 0.15 & 0.27 & 0.14 & 0.12 \\
\hline
\end{tabular}

\section{Visibility of Newspaper Characters}

Figure 5 shows the simulations of visibility of the newspaper characters when the IOLs were decentered 0 , 0.5 and $1.0 \mathrm{~mm}$. When we used ReSTOR, the characters became slightly more blurred at a $0.5-\mathrm{mm}$ decentration than at a $0-\mathrm{mm}$ decentration. At a decentration of 1.0 $\mathrm{mm}$, the degree of blurring became greater and the characters became difficult to distinguish. When we used ZM900 at decentrations of 0.5 and $1.0 \mathrm{~mm}$, the contrast of the newspaper characters decreased slightly, but not enough to affect visibility. When we used ReZoom and SFX-MV1, a decentration of even $1.0 \mathrm{~mm}$ had almost no effect on the visibility of the newspaper characters.

\section{Far MTF}

Figure 6 shows the far MTF values ( 50 cycles $/ \mathrm{mm}$ ) for each IOL decentration of $0-1.0 \mathrm{~mm}$. Table 2 shows MTF measurement values at 50 cycles $/ \mathrm{mm}$ for each IOL.

When we used ReSTOR, a reverse phenomenon occurred in which the far MTF increased with increasing decentration: the far MTF at 50 cycles/mm was 0.45 at a decentration of $0 \mathrm{~mm}$ and 0.52 at a decentration of 1.0 $\mathrm{mm}$. For ZM900, the far MTF decreased gradually with increasing decentration.

For the ReZoom, the far MTF decreased greatly at a decentration of $1.0 \mathrm{~mm}$. For SFX-MV1, the far MTF decreased greatly at a decentration of $0.75 \mathrm{~mm}$. 
ReSTOR

Decentration $0 \mathrm{~mm}$

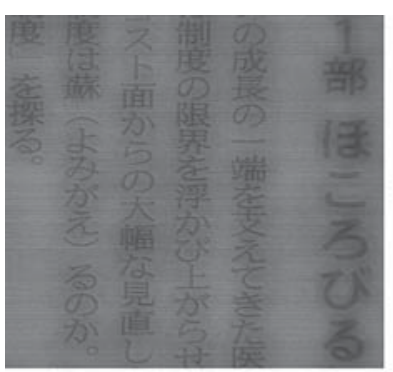

Decentration $0.5 \mathrm{~mm}$

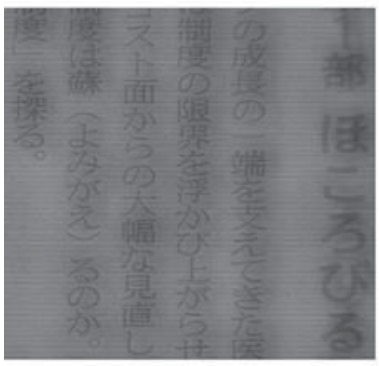

Decentration $1.0 \mathrm{~mm}$

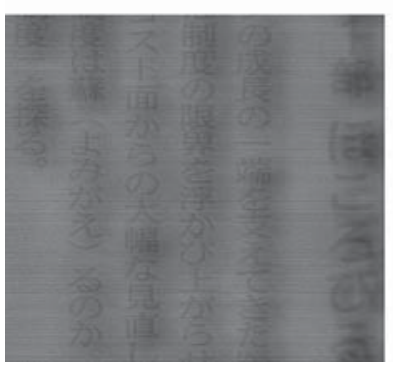

ZM900

Decentration $0 \mathrm{~mm}$

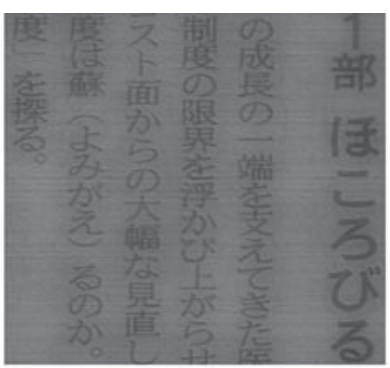

Decentration $0.5 \mathrm{~mm}$

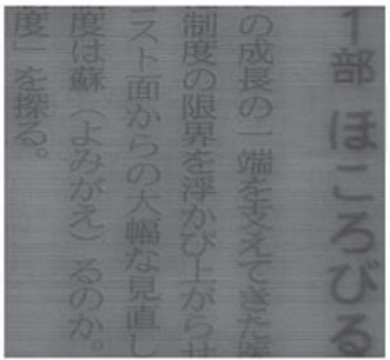

Decentration $1.0 \mathrm{~mm}$

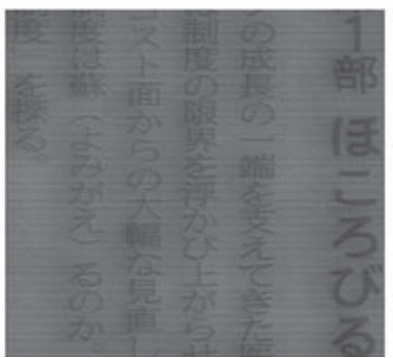

ReZoom

Decentration $0 \mathrm{~mm}$

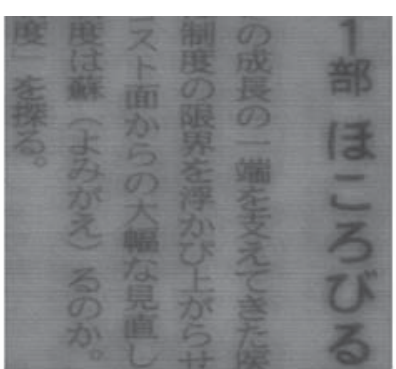

Decentration $0.5 \mathrm{~mm}$

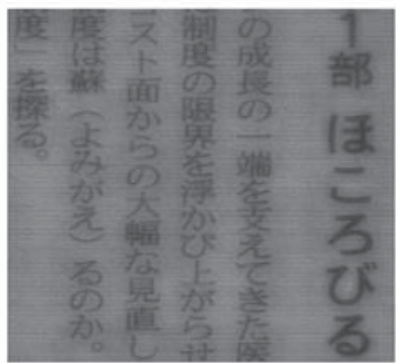

Decentration $1.0 \mathrm{~mm}$

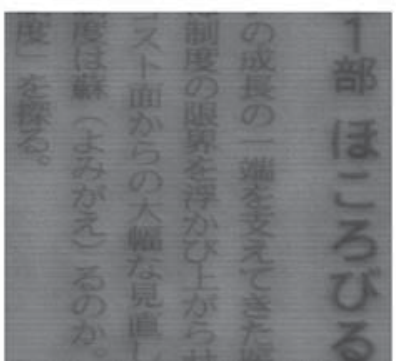

SFX-MV1

Decentration $0 \mathrm{~mm}$

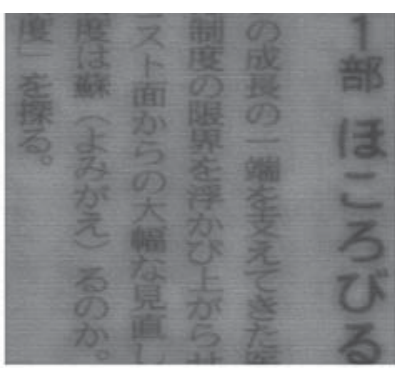

Decentration $0.5 \mathrm{~mm}$

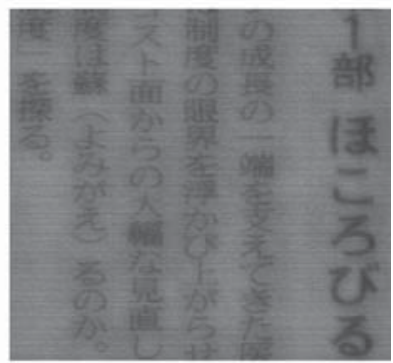

Decentration $1.0 \mathrm{~mm}$

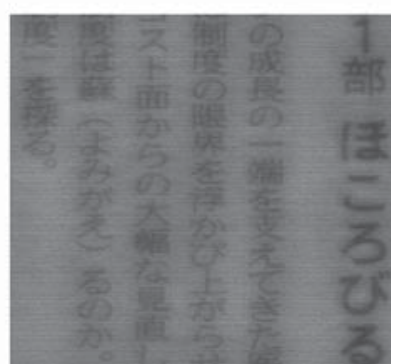

Fig. 5. The simulations of visibility of the newspaper characters using eye models.

\section{Discussion}

In this study, we used eye models to objectively evaluate the effects of multifocal IOL decentration. We quantified the effects of decentration on visual function by measuring MTF, an indicator of optical properties. Furthermore, we evaluated near images by the visibility of newspaper characters, because they are familiar in everyday life, and we comprehensively investigated how much of an actual effect could be expected.

For the diffractive ReSTOR, the near MTF tended to decrease but the far MTF tended to improve with increasing decentration. In particular, the newspaper characters became difficult to distinguish at a decentration of 1.0 $\mathrm{mm}$. ReSTOR has a diffractive structure from its center

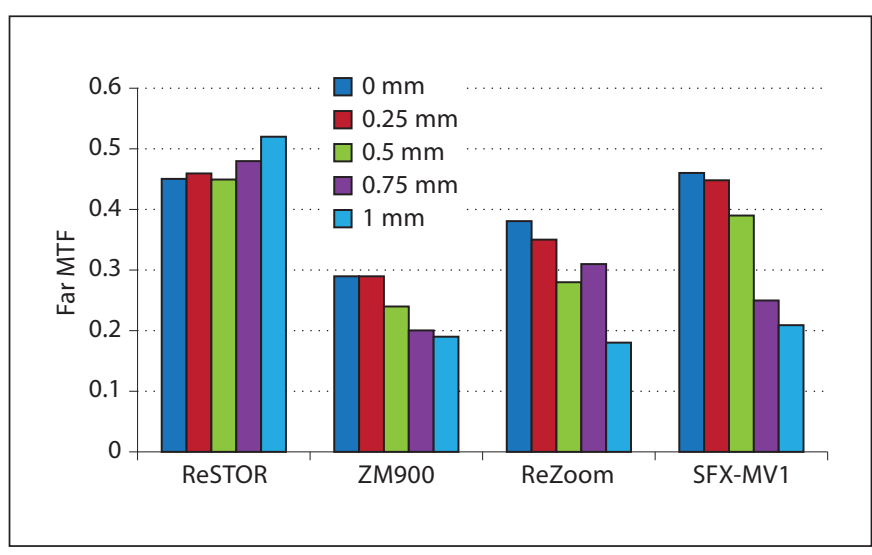

Fig. 6. Far MTF at 50 cycles $/ \mathrm{mm}$ for each IOL up to decentrations of $0-1.0 \mathrm{~mm}$. 


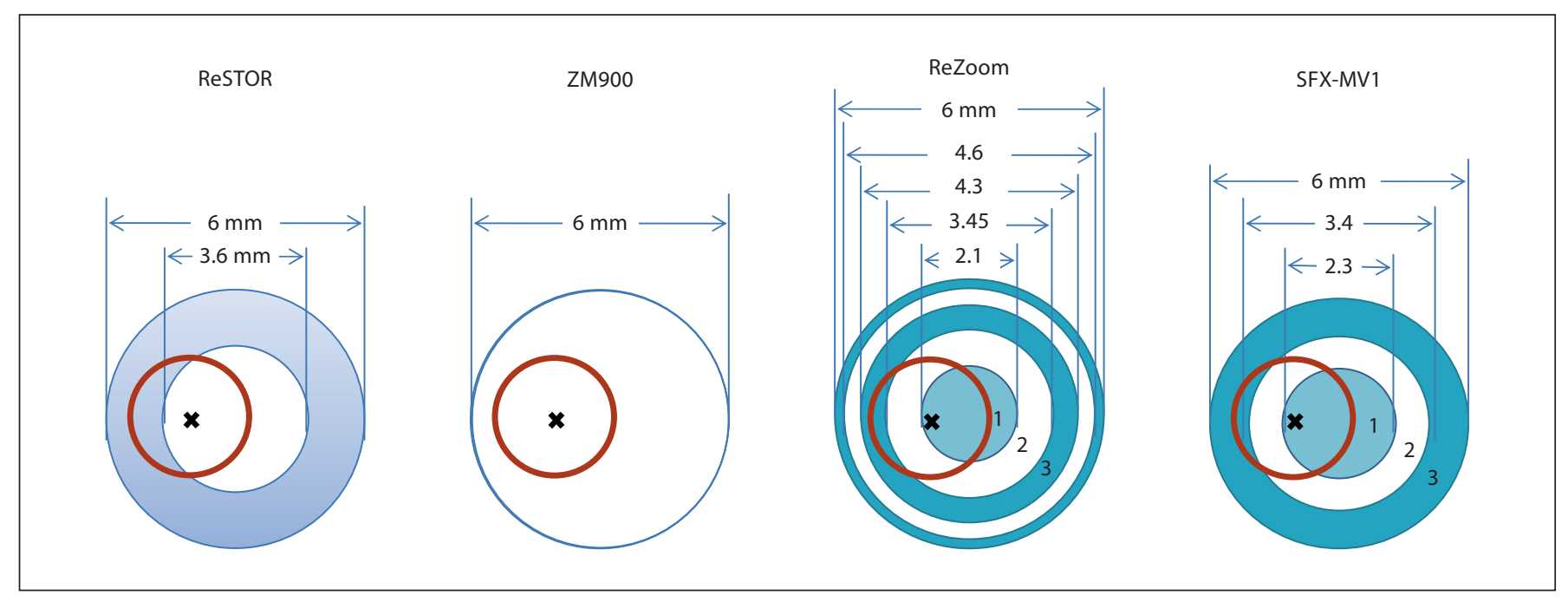

Fig. 7. Schematic diagram of a decentration of $1.0 \mathrm{~mm}$ with a multifocal IOL structure and a pupil diameter of $3 \mathrm{~mm}$. The black circle (brown in the online version) is a $3-\mathrm{mm}$ pupil, and the $\mathrm{x}$ is the center of the pupil. The IOL is horizontally decentered $1.0 \mathrm{~mm}$ to the right of the center of the pupil.

Table 2. Far MTF measurement values at 50 cycles $/ \mathrm{mm}$ for each IOL

\begin{tabular}{lllll}
\hline & ReSTOR & ZM900 & ReZoom & SFX-MV1 \\
\hline Decentration 0 mm & 0.45 & 0.29 & 0.38 & 0.46 \\
Decentration $0.25 \mathrm{~mm}$ & 0.46 & 0.29 & 0.35 & 0.45 \\
Decentration $0.5 \mathrm{~mm}$ & 0.45 & 0.24 & 0.28 & 0.39 \\
Decentration $0.75 \mathrm{~mm}$ & 0.48 & 0.2 & 0.31 & 0.25 \\
Decentration $1 \mathrm{~mm}$ & 0.52 & 0.19 & 0.18 & 0.21 \\
\hline
\end{tabular}

to a radius of $3.6 \mathrm{~mm}$, and its periphery has a monofocal structure for distance vision. Furthermore, ReSTOR is also designed such that the diffraction grating rulings at the center of the diffractive portion decrease toward its periphery in order to focus light for distance vision (apodized structure). Consequently, when a decentration is produced, a small portion of the diffraction area near the center (the prime area for near vision) is used (fig. 7). As the decentration becomes greater, a greater proportion of the monofocal area of the periphery is used. Since the monofocal area is for distance vision, the far MTF increases, and because the use of the diffractive area for near vision decreases accordingly, the near MTF decreases. Therefore, we thought that near vision was easily affected by decentration of this IOL. For diffractive ZM900, the near and far MTFs gradually decreased with increasing decentration. In the newspaper character simulation, the contrast decreased slightly, but not enough to affect the ability to distinguish the characters. For ZM900, the entire surface of the optical portion has a diffraction structure that divides incident light equally into two focal points, one for distance vision and one for near vision. Therefore, in this simulation, near vision was the least affected by decentration (fig. 7). Furthermore, the effects of decentration on distance and near vision tended to be the same, and we observed a slight decrease in far and near MTF starting at a decentration of $0.75 \mathrm{~mm}$. We thought that one factor causing this decrease may have been an increase in aberration due to increased peripheral vision of the optical portion [18]. However, since the ZM900 has an aspherical structure, the result may change if the diameter of the pupil is larger than the $3 \mathrm{~mm}$ used in this experiment; therefore, we think caution may be necessary.

Although they were not included in the present study, there are two other diffractive multifocal IOL models: the ReSTOR SN6AD1 (Alcon) and the TECNIS Multifocal ZMB00 (AMO). The ReSTOR SN6AD1, which is basically the same design as previous models, is aspheric and has an add power of $+3.0 \mathrm{dpt}$. Pupil diameter is thought to affect performance, but MTF is expected to be much lower due to deflection. The TECNIS Multifocal ZMB00 is a one-piece acrylic lens with an optical structure identical to the ZM900. Thus, the influence of deflection is likely to be the same as in the ZM900. These IOLs will require additional research in the future. 
For the refractive ReZoom and SFX-MV1, even when the decentration was $1.0 \mathrm{~mm}$, the near MTF did not change much, and there was almost no change in the visibility of the newspaper characters. However, the far MTF clearly decreased starting at a decentration of 1.0 $\mathrm{mm}$ for ReZoom and $0.75 \mathrm{~mm}$ for SFX-MV1. For the diffractive ReZoom and SFX-MV1, there was a decrease in the area of the zone used for distance vision in the center of the pupil, and there was an increase in the area of zone 2 used for near vision and that of zone 3 used for distance vision (fig. 7). The proportions of the pupil diameter occupied by the zones for distance vision and for near vision were not much different. Therefore, the effect of decentration on near vision can be considered low. However, when the decentration became as large as 0.75 and $1.0 \mathrm{~mm}$, the far MTF may have decreased since the location of the zone for near vision was near the center of the pupil. Furthermore, although not examined in this study, when the boundaries of the zones for distance vision and near vision are located in the center of the pupil, glare is highly likely to increase, and therefore caution may be necessary.

Based on these results, we will now consider the following problems in clinical cases. Normally, surgery is completed without complications, and when an IOL is inserted into the bag, the decentration may decrease to about $0.3 \mathrm{~mm}[13,19]$. In this simulation, we observed almost no changes in the far and near MTFs for all multifocal IOLs at a decentration of $0.25 \mathrm{~mm}$, therefore a decentration of about $0.3 \mathrm{~mm}$ may not have any effect on visual function. If a tear develops in the anterior capsule and an IOL is inserted into it, decentration may become about $0.5 \mathrm{~mm}$. For both the refractive and diffractive IOLs in this simulation, a decentration of about $0.5 \mathrm{~mm}$ would not be expected to cause much deterioration in optical properties; therefore, the degree of decentration due to the anterior capsule is probably within an acceptable range.

At decentrations of around $0.75-1.0 \mathrm{~mm}$, deterioration in optical properties does not easily occur when inthe-bag fixation is used. Decentration may occur as a result of out-of-the-bag fixation, suture fixation of the IOL or a brittle zonule of Zinn. At a decentration of $1.0 \mathrm{~mm}$, there is a difference between the deterioration in optical properties of the IOLs, and the effect that this has on visual function cannot be avoided. Therefore, as a rule, the multifocal IOL should probably be inserted into the capsule afterall, and the degree of decentration due to tears in the anterior capsule will probably be within an acceptable range. There are several problems with this study.
First, central actions in the human eye such as binocular vision, adaptation and ocular dominance were not considered because the study was an in vitro experiment using eye models. With the eye model, only an optical system was simulated. Therefore, visual images by the human eye and images by the eye model are not necessarily consistent, and visual images by the human eye may be sharper than images by the eye model. However, the eye model can be considered useful for comparing the inherent characteristics of IOLs because it does not have central actions. Furthermore, if the eye model does not affect optical properties, it also seems unlikely that human eyes would have clinical effects.

In addition, we investigated the effect on decentration only on the horizontal axis in this study. We did not investigate the decentration on the vertical or oblique axes. However, because the IOLs in this study had a structure of concentric circles from the center radiating toward the periphery, we believe that the possibility of largely skewed results due to the direction of decentration is small.

Moreover, we have only studied the effects of decentration and have not evaluated the tilt of the IOLs. Clinically, decentration and tilt often occur simultaneously; therefore, we would like to continue creating new experimental models and studying these phenomena. In this study, we objectively evaluated the effects of decentration of multifocal IOLs by simulations of far and near MTFs, and near images using two types of eye models. The effects of decentration had different characteristics for each multifocal IOL, but we expect the effect on visual function to be minimal when the decentration is $0.75 \mathrm{~mm}$ or less. Simulation using the eye model appears to be useful for the objective evaluation of IOLs.

References

1 Mester U, Dillinger P, Anterist N: Impact of a modified optic design on visual function: clinical comparative study. J Cataract Refract Surg 2003;29:652-660

2 Ohtani S, Miyata K, Samejima T, Honbou M, Oshika T: Intraindividual comparison of aspherical and spherical intraocular lenses of same material and platform. Ophthalmology 2009;116:896-901.

- 3 Holland E, Lane S, Horn JD, Ernest P, Arleo R, Miller KM: The AcrySof Toric intraocular lens in subjects with cataracts and corneal astigmatism: a randomized, subject-masked, parallel-group, 1-year study. Ophthalmology 2010;117:2104-2111. 
-4 Ahmed II, Rocha G, Slomovic AR, Climenhaga $\mathrm{H}$, Gohill J, Grégoire A, Ma J: Visual function and patient experience after bilateral implantation of toric intraocular lenses. J Cataract Refract Surg 2010;36:609-616.

5 Ruíz-Mesa R, Carrasco-Sánchez D, Díaz-Alvarez SB, Ruíz-Mateos MA, Ferrer-Blasco T, Montés-Micó R: Refractive lens exchange with foldable toric intraocular lens. Am J Ophthalmol 2009;147:990-996.

-6 Souza CE, Muccioli C, Soriano ES, Chalita MR, Oliveira F, Freitas LL, Meire LP, Tamaki C, Belfort R Jr: Visual performance of Acrysof ReSTOR apodized diffractive IOL: a prospective comparative trial. Am J Ophthalmol 2006;141:827-832.

7 Blaylock JF, Si Z, Vickers C: Visual and refractive status at different focal distances after implantation of the ReSTOR multifocal intraocular lens. J Cataract Refract Surg 2006;32:1464-1473.

-8 Chiam PJT, Chan JH, Aggarwal RK Karia N, Kasaby H, Aggarwal RK: Functional vision with bilateral ReZoom and ReSTOR intraocular lenses 6 months after cataract surgery. J Cataract Refract Surg 2007;32:14591463.

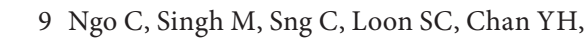
Thean L: Visual acuity outcomes with SA60D3, SN60D3, and ZM900 multifocal IOL implantation after phacoemulsification. J Cataract Refract Surg 2010;26:177-182.

10 Cilino S, Casuccio A, Di Pace F, Morreale R, Pillitteri F, Cillino G, Lodato G: One-year outcomes with new-generation multifocal intraocular lenses. Ophthalmology 2008; 115:1508-1516.

11 Hayashi K, Yosida M, Hayashi H: All-distance visual acuity and contrast visual acuity in eyes with a refractive multifocal intraocular lens with minimal added power. Ophthalmology 2009;116:401-408.

-12 Negishi K, Ohnuma K, Ikeda T, Noda T: Visual simulation of retina images through a decentered monofocal and a refractive multifocal intraocular lens. J Jpn Ophthalmol Soc 2005;49:281-286.

13 Hayashi K, Hayashi H, Nakao F, Hayashi F: Correlation between pupillary size and intraocular lens decentration and visual acuity of a zonal-progressive multifocal lens and a monofocal lens. Ophthalmology 2001;108: 2011-2017.
14 Yukiko K, Toshikatsu N, Shigeo Y, Tadahiko $\mathrm{K}$, Masanobu K: The retinal image of three multifocal intraocular lenses through an eye model. J Jpn Ophthalmol Soc 1994;98:10911096.

15 Soda M, Yaguchi S: Simulation of retinal image using the eye model for objective evaluation of multifocal intraocular lenses (in Japanese) J Ophthal Surg 2009;22:240-244.

16 Yaguchi S, Soda M: Visual simulation of retinal images through new generation multifocal intraocular lenses. Jpn J Cataract Refract Surg 2009;23:214-223.

17 Kawamorita T, Uozato H: Modulation transfer function and pupil size in multifocal and monofocal intraocular lenses in vitro. J Cataract Refract Surg 2005;31:2379-2385.

18 Eppig T, Scholz K, Loffer A, Meisner A, Langenbucher A: Effect of decentration and tilt on the image quality of aspheric intraocular lens designs in eye models. J Cataract Refract Surg 2009;35:1091-1100.

19 Yang HC, Chung SK, Baek NH: Decentration, tilt, and near vision of the Array multifocal intraocular lens. J Cataract Refract Surg 2000;26:586-589. 